\title{
Repair for the Anomalies of Ventriculoarterial Connection with Ventricular Septal Defect and Left Ventricular Outflow Tract Obstruction
}

\author{
Woong-Han Kim*, Jeong Ryul Lee, Yong Jin Kim \\ From World Society of Cardiothoracic Surgeons 25th Anniversary Congress, Edinburgh \\ Edinburgh, UK. 19-22 September 2015
}

\section{Background/Introduction}

Anomalies of ventriculoarterial connection with ventricular septal defect (VSD) and left ventricular outflow tract (LVOT) obstruction such as transposition of the great arteries, double-outlet right ventricle, double-outlet left ventricle, and Taussig-Bing anomaly had a wide variety of spectrum, and several operative techniques have been performed according to diverse anatomical characteristics without standard operative selection guidelines.

\section{Aims/Objectives}

This study was undertaken to compare the outcomes of the Lecompte procedure and Rastelli repair in anomalies of ventriculoarterial connection with VSD and LVOT obstruction.

\section{Method}

Over a 35-year period (1979-2014), 95 patients underwent complete repair for anomalies of ventriculoarterial connection with VSD and LVOT obstruction. Fifty patients (52.6\%) underwent the Lecompte modification, and median age and weight were 1.95 years (range: $0.30-12.48$ ) and $10.1 \mathrm{~kg}$ (range: $5.7-35$ ). Forty five patients $(47.4 \%)$ underwent the Rastelli operation, and median age and weight were 3.25 years (range: 0.36 46.15 ) and $13.0 \mathrm{~kg}$ (range: $5.9-55)$.

\section{Results}

There were thirteen deaths after complete repair. Twenty three (46.0\%) patients in the Lecompte group underwent reoperation, and thirty three $(73.3 \%)$ in the
Rastelli group underwent reoperation. Freedom from reoperation was $25.2 \pm 9.4 \%$ at 25 years in the Lecompte group and $5.5 \pm 4.8 \%$ at 27 years in the Rastelli group $(\mathrm{p}=0.01)$. Freedom from reoperation for right ventricular outflow tract (RVOT) obstruction was $49.6 \pm 9.0 \%$ at 25 years in the Lecompte group and $6.8 \pm 5.8 \%$ at 27 years in the Rastelli group $(\mathrm{p}=0.01)$. Freedom from reoperation for LVOT obstruction was $88.5 \pm 5.4 \%$ at 25 years in the Lecompte group and $60.7 \pm 10.4 \%$ at 33 years in the Rastelli group ( $\mathrm{p}=0.01$ ).

\section{Discussion/Conclusion}

The Lecompte procedure and Rastelli repair provide satisfactory results at long-term follow-up. Substantial late morbidity is more associated with RVOT obstruction, and LVOT obstruction in Rastelli repair rather than Lecompte procedure.

Published: 16 December 2015

doi:10.1186/1749-8090-10-S1-A83

Cite this article as: Kim et al:: Repair for the Anomalies of Ventriculoarterial Connection with Ventricular Septal Defect and Left Ventricular Outflow Tract Obstruction. Journal of Cardiothoracic Surgery 2015 10(Suppl 1):A83. 